\title{
Measuring the effects of electronic learning components using ANFIS method
}

\author{
Mahdi Bahrami $^{\mathrm{a}^{*}}$, Mir Mehrdad Peidaie ${ }^{\mathrm{b}}$ and Nazanin Pilevari ${ }^{\mathrm{b}}$
}

${ }^{a}$ Department of Information Technology, Electronic Branch, Islamic Azad University, Senior Auditor in supreme Audit court ,Tehran, Iran ${ }^{b}$ Assistant Professor, Shahr-E-Rey Branch, Islamic Azad University, Iran

\section{H R O N I C L E}

\begin{tabular}{l}
\hline Article history: \\
Received October 28, 2013 \\
Received in revised format \\
20 November 2013 \\
Accepted 12 January 2014 \\
Available online \\
January 152014 \\
\hline Keywords: \\
Electronic learning \\
Islamic Azad University \\
Electronic content
\end{tabular}

\begin{abstract}
A B S T R A C T
Electronic learning is getting popular in the world and more universities are offering various courses through internet. This paper presents an empirical investigation on effectiveness of electronic courses in one of Iranian universities whose students were enrolled on electronic learning. The proposed study designs a questionnaire to measure the effects of this program in terms of teaching, administration and electronic content, and distributes it among 354 randomly selected students. Cronbach alpha has been calculated as 0.97 , which is well above the minimum acceptable level. The study gathers all inputs in Likert scale in terms of linguistic variables. The study uses ANFIS to measure to analyze the data and the results indicate that electronic learning itself maintains the highest popularity among students $(0.618)$ followed by electronic content (0.569) and administration efforts (0.563).
\end{abstract}

\section{Introduction}

During the past two decades, there has been growing interest among universities on resorting to electronic learning (e-Learning) as a tool for solving authentic learning and performance problems (Ong et al., 2004; Kahiigi et al., 2007; Macpherson et al., 2007). Success is important and one of the most important requirements for successful use of e-Learning is the necessity for careful consideration of the underlying pedagogy, or how learning happens online. Govindasamy (2001) identified the pedagogical principles underlying the teaching and learning activities that constitute effective e-Learning. Selim (2007) specified e-learning critical success factors (CSFs) as perceived by university students. The published e-learning CFSs were surveyed and grouped into 4 groups namely, instructor, student, information technology, and university support. The study was examined by surveying 538 university students and the results disclosed 8 categories of e-learning CSFs, each included various critical e-learning acceptance and success measures.

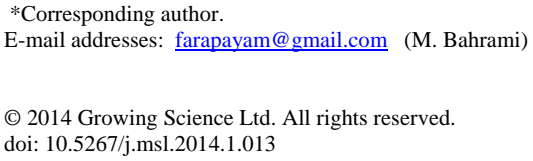


Ong and Lai (2006) investigated gender differences in perceptions and relationships among dominants of e-learning acceptance. They reported that women were more strongly affected by perceptions of computer self-efficacy and ease of implementation, and that men's usage decisions were more substantially affected by their perception of usefulness of e-learning. The results also recommended that researchers should take into consideration factors of gender in the development and examining of e-learning theories. Managers and co-workers, moreover, should understand that elearning could be perceived differently by women and men.

Macpherson et al. (2005) evaluated the use and implementation of e-learning through case material, and explored some of the challenges and emerging concerns. They argued that when corporate universities did not incorporate both the pedagogical and learner preferences perspectives into their implementation of e-learning, this would seriously devalue the training experience. Liaw et al. (2007) investigated instructors' and learners' behaviors toward e-learning usage and reported that instructors had positive perceptions toward using e-learning as a teaching assisted tool. Furthermore, behavioral intention to implement e-learning was influenced by perceived usefulness and self-efficacy. WelleStrand and Thune (2003) investigated e-learning policies, practices and challenges in two Norwegian organizations. The findings stated that there was insufficient follow-up on e-learning policies and that there was a general lack of strategic direction and leadership in this area. Ozkan and Koseler (2009) performed an empirical investigation on multi-dimensional students' evaluation of e-learning systems in the higher education context. The study proposed a conceptual e-learning assessment model, hexagonal e-learning assessment model (HELAM) recommending a multi-dimensional method for LMS evaluation via six dimensions: (1) system quality, (2) service quality, (3) content quality, (4) learner perspective, (5) instructor attitudes, and (6) supportive issues. They reported that each of the six dimensions of the proposed model had a significant impact on the learners' perceived satisfaction.

\section{The propose method}

This paper presents an empirical investigation on effectiveness of electronic courses in one of Iranian universities whose students were enrolled on electronic learning. The proposed study designs a questionnaire to measure the effects of this program in terms of teaching, administration and electronic content. Fig. 1 demonstrates the proposed structure of the proposed model.

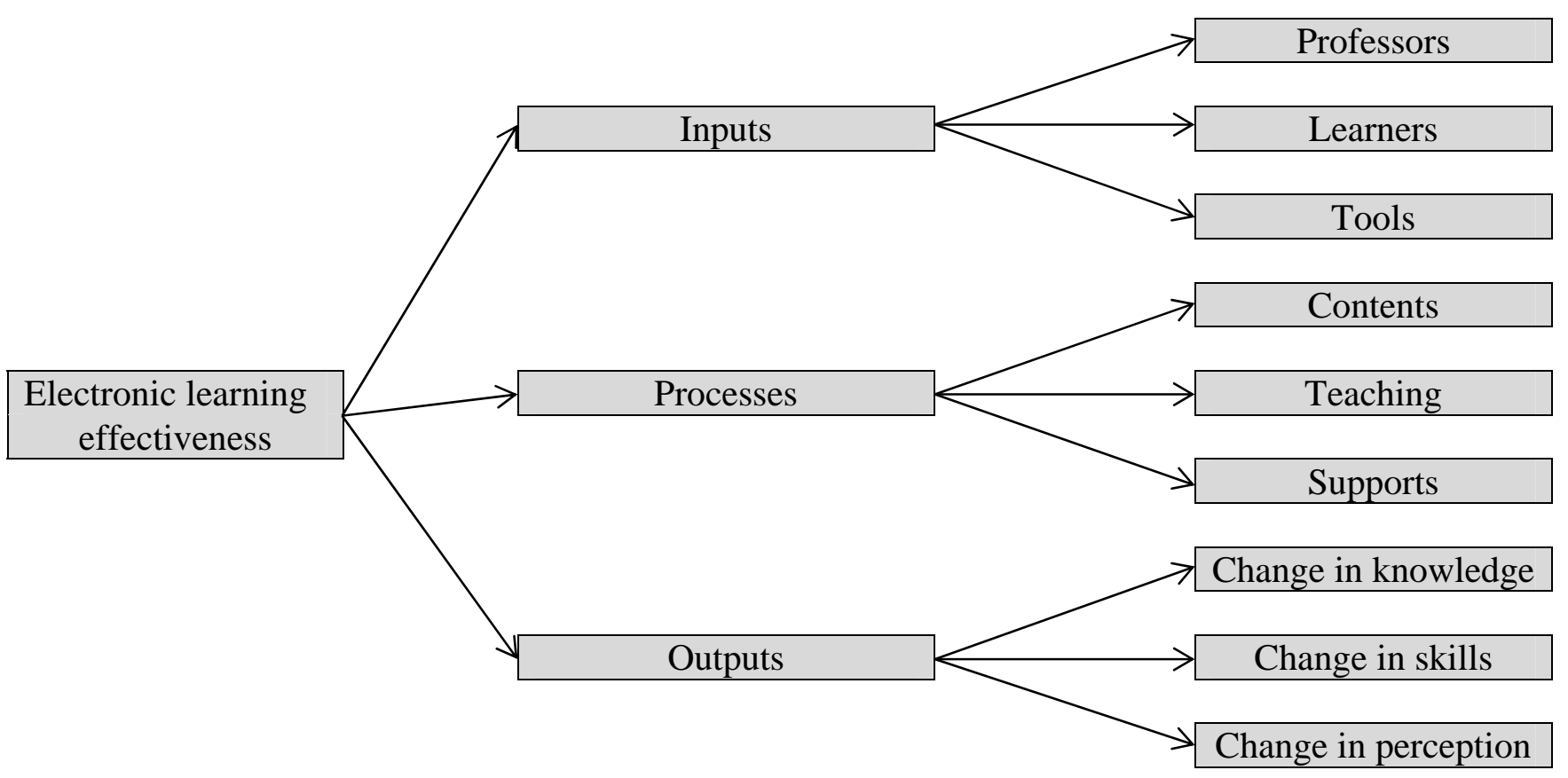

Fig. 1. The framework of the proposed study 
As we can observe from the results of Fig. 1, electronic learning is investigated in terms of three components of inputs, processes and outputs. There are three components professors, learners and tools associated with inputs. In addition, processes include contents, teaching and supports and outputs are measured based on changes in knowledge, skills and perception. The study has been accomplished among 1219 graduate students who were enrolled at Islamic Azad University, electronic unit. The sample size is calculated as follows,

$n=\frac{N \times z_{\alpha / 2}^{2} \times p \times q}{\varepsilon^{2} \times(N-1)+z_{\alpha / 2}^{2} \times p \times q}$,

where $N$ is the population size, $p=1-q$ represents the yes/no categories, $z_{\alpha / 2}$ is CDF of normal distribution and finally $\varepsilon$ is the error term. Since we have $p=0.5, z_{\alpha / 2}=1.96$ and $N=1219$, the number of sample size is calculated as $n=292$. The proposed study designs a questionnaire to measure the effects of this program in terms of teaching, administration and electronic content, and distributes it among 354 randomly selected students.

Cronbach alpha has been calculated as 0.97, which is well above the minimum acceptable level. All data are gathered in terms of linguistic variables and they are processed using ANFIS method. The method gathers the input data in terms of triangular numbers $(a, m, b)$ and they are converted based on $X=m+(b-a) / 4$. Table 1 shows details of the linguistic terms used for the proposed model of this paper.

\section{Table 1}

The summary of linguistic terms

\begin{tabular}{lcc}
\hline Linguistic terms & Triangular number & Crisp number \\
\hline Completely agree & $(0,0.25,1)$ & 0.9375 \\
Agree & $(0.15,0.15,0.75)$ & 0.75 \\
No difference & $(0.25,0.25,0.50)$ & 0.5 \\
Disagree & $(0.15,0.15,0.25)$ & 0.25 \\
Completely disagree & $(0,00.25)$ & 0.0625 \\
\hline
\end{tabular}

The ANFIS model maintains three-stage system of training, testing and checking the data. Fig 2 shows details of two stages of the proposed study, testing and checking.

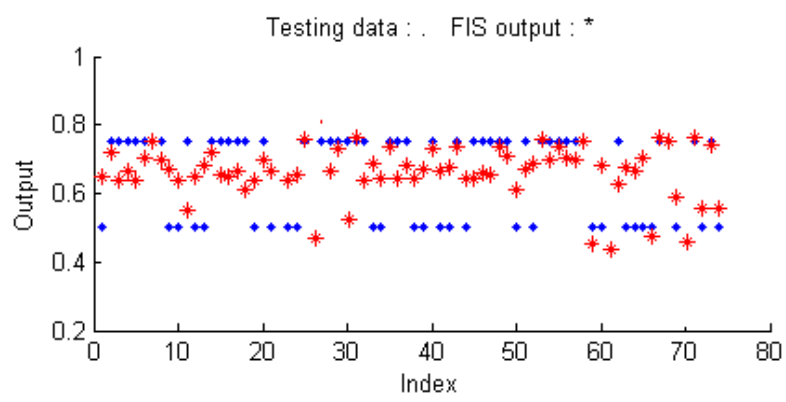

Testing

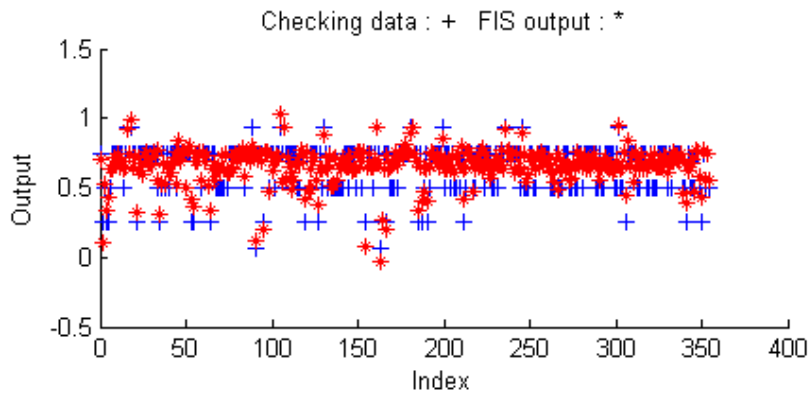

Checking

Fig. 2. Trends for testing and checking the data

In Fig. 2, the data shown with $(+)$ are processed data and $(*)$ represent output data and these two sets of data seem to be close to each other. Table 2 shows details of the simultaneous changes on inputs and the outputs. 
Table 2

The summary of changes on input/output

\begin{tabular}{cccc}
\hline & Inputs & & Output \\
\hline Input & Process & Output & Electronic learning effectiveness \\
\hline 0 & 0 & 0 & -0.152 \\
0.50 & 0.50 & 0.50 & 0.635 \\
1.00 & 1.00 & 1.00 & 1.15 \\
\hline
\end{tabular}

\section{The results}

In this section, we present details of our findings on the implementation of ANFIS in terms of three figures of input, process as well as output.

\subsection{Input}

We first present details of our findings in terms of inputs shown in Fig. 3 as follows,

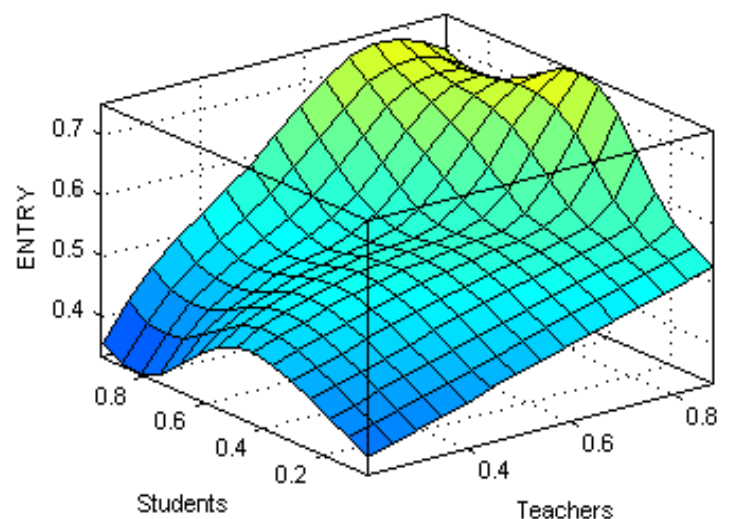

The effects of professors and students on inputs

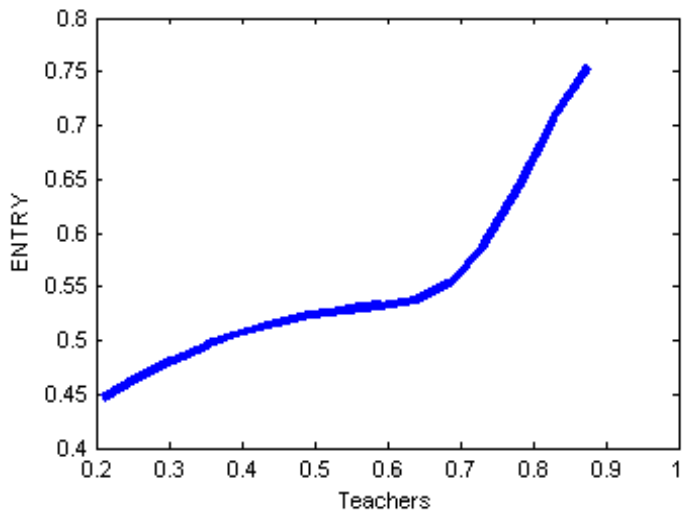

The effects of professors on inputs

Fig. 3. The effects of university students and professors on inputs

As we can observe from the results of Fig. 3, teachers have smooth effect on inputs up to a level of 0.70 and the trends increase exponentially after that level.

\subsection{The processes}

The second component of the survey is associated with different processes including content, administration as well as supporting efforts. Fig. 4 demonstrates the summary of our findings.

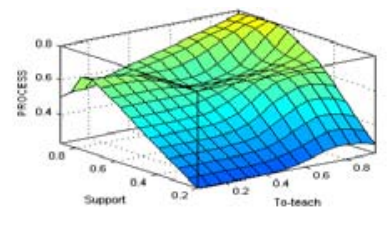

Extracting data for content, electronic learning and administration

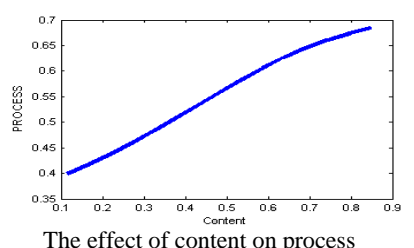

Fig. 4. The results of different factors on process

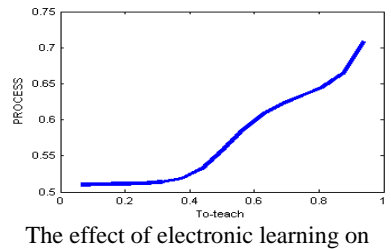
process

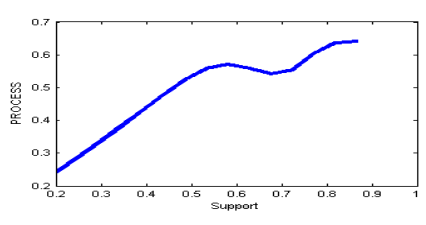

The effect of administration on process 
According to the results of Fig. 4 the effect of content on process is to a level of 0.8 and after that level, the effect becomes smooth. In addition, electronic learning on process starts with low rates and then it increases rapidly. Finally, administrations as well as supporting efforts maintain positive efforts on process.

\subsection{The effects of outputs}

Outputs are the third components of the survey and Fig. 5 shows details of our findings as follows,
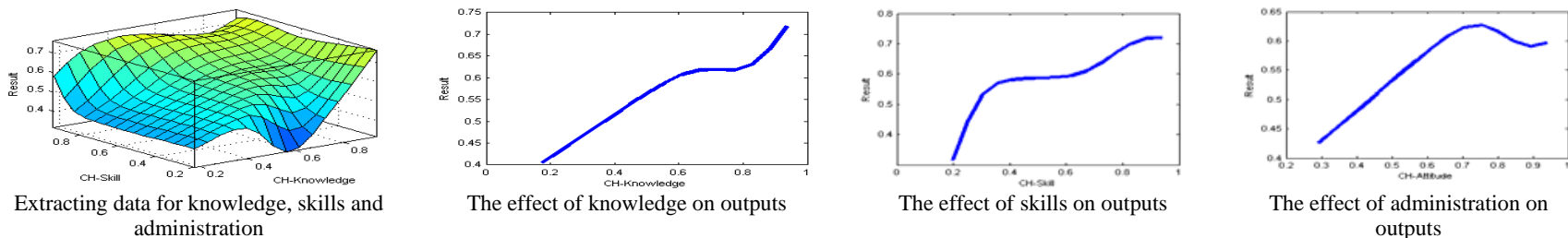

Fig. 5. The results of different factors on outputs

The results of Fig. 5 clearly show that the increase on knowledge, skills as well as administration efforts increase outputs, significantly.

\section{Conclusion}

In this paper, we have presented an empirical investigation to study the effects of different factors on electronic learning in one of Iranian universities, which was active in the field of electronic learning. The study uses ANFIS to measure to analyze the data and the results indicate that electronic learning itself maintains the highest popularity among students (0.618) followed by electronic content $(0.569)$ and administration efforts (0.563). Table 3 demonstrates the summary of our findings.

\section{Table 3}

The summary of findings on the effects of various factors on electronic learning

\begin{tabular}{ccc}
\hline Dimension & Component & Mean of feedbacks \\
\hline \multirow{2}{*}{ Inputs } & Teachers & 0.608 \\
0.629 & Students & 0.648 \\
& Information technology & 0.633 \\
\hline \multirow{2}{*}{ Process } & Content & 0.569 \\
0.584 & Teaching & 0.620 \\
& Administration & 0.563 \\
\hline \multirow{2}{*}{ Output } & Change in knowledge & 0.637 \\
& Change in skills & 0.643 \\
\end{tabular}

According to the results of Table 3, in terms of inputs, students play the most important role followed by information technology. In terms of processes, teaching plays essential role followed by content generation. Finally, output is the last item where change in perception is the most important component of the survey.

\section{Acknowledgement}

The authors would like to thank the anonymous referees for constructive comments on earlier version of this paper. We are also delighted for the cooperation of officials of Islamic Azad University. 


\section{References}

Govindasamy, T. (2001). Successful implementation of e-learning: Pedagogical considerations. The Internet and Higher Education, 4(3), 287-299.

Kahiigi, E., Ekenberg, L., \& Hansson, M. (2007). Exploring the e-Learning State of art. In Conference on E-Learning, Academic Conferences Limited (pp. 349-368).

Liaw, S. S., Huang, H. M., \& Chen, G. D. (2007). Surveying instructor and learner attitudes toward elearning. Computers \& Education, 49(4), 1066-1080.

Macpherson, A., Elliot, M., Harris, I., \& Homan, G. (2004). E-learning: Reflections and evaluation of corporate programmes. Human Resource Development International, 7(3), 295-313.

Macpherson, A., Homan, G., \& Wilkinson, K. (2005). The implementation and use of e-learning in the corporate university. Journal of Workplace Learning,17(1/2), 33-48.

Ong, C. S., Lai, J. Y., \& Wang, Y. S. (2004). Factors affecting engineers' acceptance of asynchronous e-learning systems in high-tech companies. Information \& management, 41(6), 795804.

Ong, C. S., \& Lai, J. Y. (2006). Gender differences in perceptions and relationships among dominants of e-learning acceptance. Computers in Human Behavior, 22(5), 816-829.

Ozkan, S., \& Koseler, R. (2009). Multi-dimensional students' evaluation of e-learning systems in the higher education context: An empirical investigation. Computers \& Education, 53(4), 1285-1296.

Selim, H. M. (2007). Critical success factors for e-learning acceptance: Confirmatory factor models. Computers \& Education, 49(2), 396-413.

Welle-Strand, A., \& Thune, T. (2003). E-learning policies, practices and challenges in two Norwegian organizations. Evaluation and program planning,26(2), 185-192. 